\author{
RESEARCH ARTICLE \\ 10.1029/2019JC015873 \\ Key Points: \\ - The Particle Finite Element Method \\ is applied to simulate the entire \\ landslide-generated wave problem \\ in a single numerical framework \\ - Numerical results in 2-D are \\ compared to large-scale \\ experimental data and are \\ qualitatively and quantitatively in \\ close agreement \\ - Complete visualization of the \\ evolution of the water surface and \\ velocity field allows for new insight \\ on tsunami generated by landslides
}

Supporting Information:

- Supporting Information S1

Correspondence to:

R. P. Mulligan,

ryan.mulligan@queensu.ca

Citation:

Mulligan, R. P., Franci, A., Celigueta, M. A., \& Take, W. A. (2020)

Simulations of landslide wave

generation and propagation using the

Particle Finite Element Method.

Journal of Geophysical Research:

Oceans, 125, e2019JC015873. https://

doi.org/10.1029/2019JC015873

Received 12 NOV 2019

Accepted 31 MAY 2020

Accepted article online 3 JUN 2020

(C)2020. American Geophysical Union. All Rights Reserved.

\section{Simulations of Landslide Wave Generation and Propagation Using the Particle Finite Element Method}

\author{
R. P. Mulligan ${ }^{1}$ (D), A. Franci ${ }^{2}$ (D), M. A. Celigueta ${ }^{2}$ (D) and W. A. Take ${ }^{1}$ iD \\ ${ }^{1}$ Department of Civil Engineering, Queen's University, Kingston, Ontario, Canada, ${ }^{2}$ Centre Internacional de Mètodes \\ Numèrics en Enginyeria (CIMNE), Barcelona, Spain
}

\begin{abstract}
In this study, the impulse waves generated by highly mobile slides in large-scale flume experiments are reproduced numerically with the Particle Finite Element Method (PFEM). The numerical technique combines a Lagrangian finite element solution with an efficient remeshing algorithm and is capable of accurately tracking the evolving fluid free-surface and velocity distribution in highly unsteady flows. The slide material is water, which represents an avalanche or debris flow with high mobility, and the reservoir depth is varied, thereby achieving a range of different near-field wave conditions from breaking waves to near-solitary waves. In situ experimental observations of fluid velocity and water surface levels are obtained using high-speed digital cameras, acoustic sensors, and capacitance wave probes, and the data are used to analyze the accuracy of the PFEM predictions. The two-dimensional numerical model shows the capability of holistically reproducing the entire problem from landslide motion, to impact with water, to wave generation, propagation, and runup. Very good agreement with the experimental observations are obtained, in terms of landslide velocity and thickness, wave time series, maximum wave amplitude, wave speed, and wave shape. In a broad perspective, the results demonstrate the potential of this numerical method for predicting outcomes of interacting multi-hazard scenarios, such as landslides triggered by loss of slope stability and the generation of tsunami.
\end{abstract}

\section{Introduction}

Waves generated when landslides transfer momentum to water (Mulligan \& Take, 2017) are major natural hazards in coastal areas of lakes, reservoir, and fjords. One example occurred in 2007 in Chehalis Lake in British Columbia, Canada, where a 3 million $\mathrm{m}^{3}$ landslide impacted a long and narrow lake. The slide generated a near-field wave with runup of $38 \mathrm{~m}$ on the opposite shore $0.5 \mathrm{~km}$ away (Brideau et al., 2012) and propagated along the lake causing runup of over $6 \mathrm{~m}$ at a recreational site $7.5 \mathrm{~km}$ from the impact zone (Roberts et al., 2013). Field cases such as this are valuable in documenting the after-effects of these waves such as the maximum runup elevations and damage; however, the landslide impact properties and near-field wave characteristics are not observable. Laboratory experiments are important for characterizing the near-field wave conditions (e.g., Evers et al., 2019; Fritz et al., 2004; Heller \& Hager, 2010; Miller et al., 2017). Risk analysis for these hazardous events needs to be based on numerical modeling to accurately simulate the wave propagation, since the far-field waves typically impact communities and infrastructure. A recent example of this was the 45 million $\mathrm{m}^{3}$ landslide into Karrat Fjord, Greenland, in 2017. This landslide generated an impact wave with a near-field runup of $90 \mathrm{~m}$ and runup of over $50 \mathrm{~m}$ on the opposite shoreline $6 \mathrm{~km}$ away (Fritz et al., 2018), and the tsunami propagated $30 \mathrm{~km}$ impacting the small community of Nuugaatsiaq (Gauthier et al., 2018).

Numerical models are useful tools for simulating impact wave transformation and propagation; however, the landslide boundary conditions must be known. For example, phase-resolving wave models can accurately simulate tsunami propagation, but the landslide motion must be prescribed by a function (e.g., Lynett \& Liu, 2005), or the incident wave must be input from measurements (e.g., Mulligan et al., 2019; Ruffini et al., 2019). This type of multi-stage approach, where several different uncoupled methods are used together, is the current state of practice. The concept is illustrated in Figure 1, where the initial and boundary conditions of the landslide and reservoir are determined (Figure 1a). The next stage is to determine the landslide properties at impact with water using a landslide dynamic model and use these to estimate the 
(a) Initial conditions

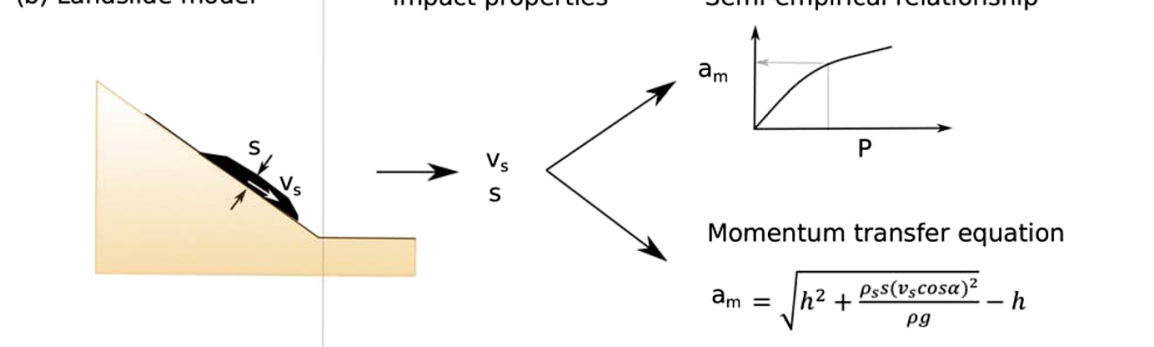

(c) Wave propagation model

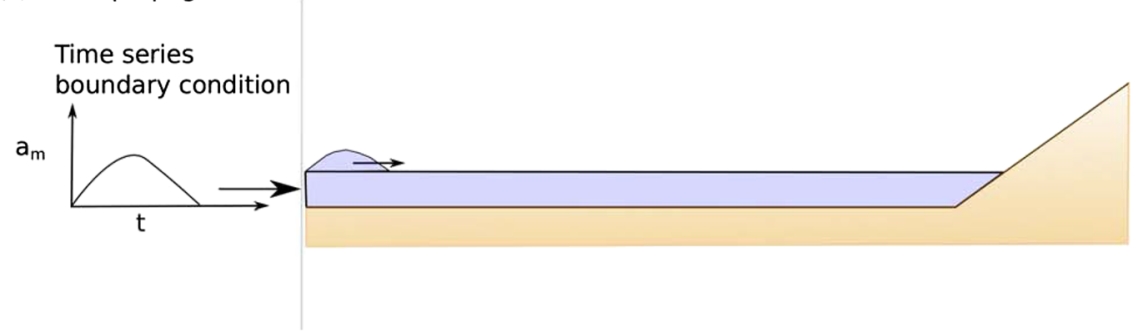

Figure 1. State of practice of prediction of landslide runup using multi-stage numerical modeling of impulse waves generated by landslides: (a) initial conditions illustrating a landslide source volume on a slope above a reservoir; (b) landslide model to predict velocity and thickness at the point of impact with the reservoir for use in semi-empirical or theoretical models of near-field maximum amplitude; and (c) near-field amplitude included into an assumed time series boundary condition for wave propagation to the far field.

maximum wave amplitude (Figure 1b) via a semi-empirical relationship (e.g., Heller \& Hager, 2010) or a momentum transfer equation (e.g., Mulligan \& Take, 2017). The wave amplitude can then be used to estimate the time series for input to a wave propagation model (Figure 1c) after considering the wave shape that could, for example, be represented by the solitary wave equation modified to account for asymmetry depending on the impact properties (Bullard, Mulligan, \& Take, 2019). The wave shape is critical, at it is also indicative of the breaking or non-breaking behavior of the near-field wave that can drastically influence the evolution of wave amplitude as it propagates to the far field.

A more holistic and state-of-the-art approach is to attempt to model the landslide, wave generation, and propagation in the same numerical modeling framework. The advantage of the holistic approach is that if the wave amplitude and shape are correct in the near-field region, then there is the potential for highly accurate predictions of the far-field waves. Several methods for modeling the complete problem of landslide impacts and wave generation in one general framework exist. These include finite volume-based non-hydrostatic models (e.g., Ma et al., 2013), two-phase mass flow models (e.g., Kafle et al., 2016; Pudasaini, 2012), finite element models with the Volume of Fluid (VOF) technique (e.g., Smith et al., 2016), coupled finite volume and finite difference Eulerian models (e.g., Kim et al., 2019), and Arbitrary Lagrangian-Eulerian (ALE) techniques (e.g., Crosta et al., 2016). Particle-based methods are also being developed such as the Material Point Method (MPM) (e.g., Pinyol et al., 2017; Yerro et al., 2019), Smoothed Particle Hydrodynamics (SPH) (e.g., Ataie-Ashtiani \& Shobeyri, 2008; Pastor et al., 2009), the Lattice-Boltzmann Method (LBM) (e.g., Pak \& Sarfaraz, 2014; Qiu et al., 2019), and the Particle Finite Element Method (PFEM) (e.g., Cremonesi et al., 2011) which show promising results. A further investigation of PFEM for landslide tsunami applications will be the primary focus of the remainder of this paper. 


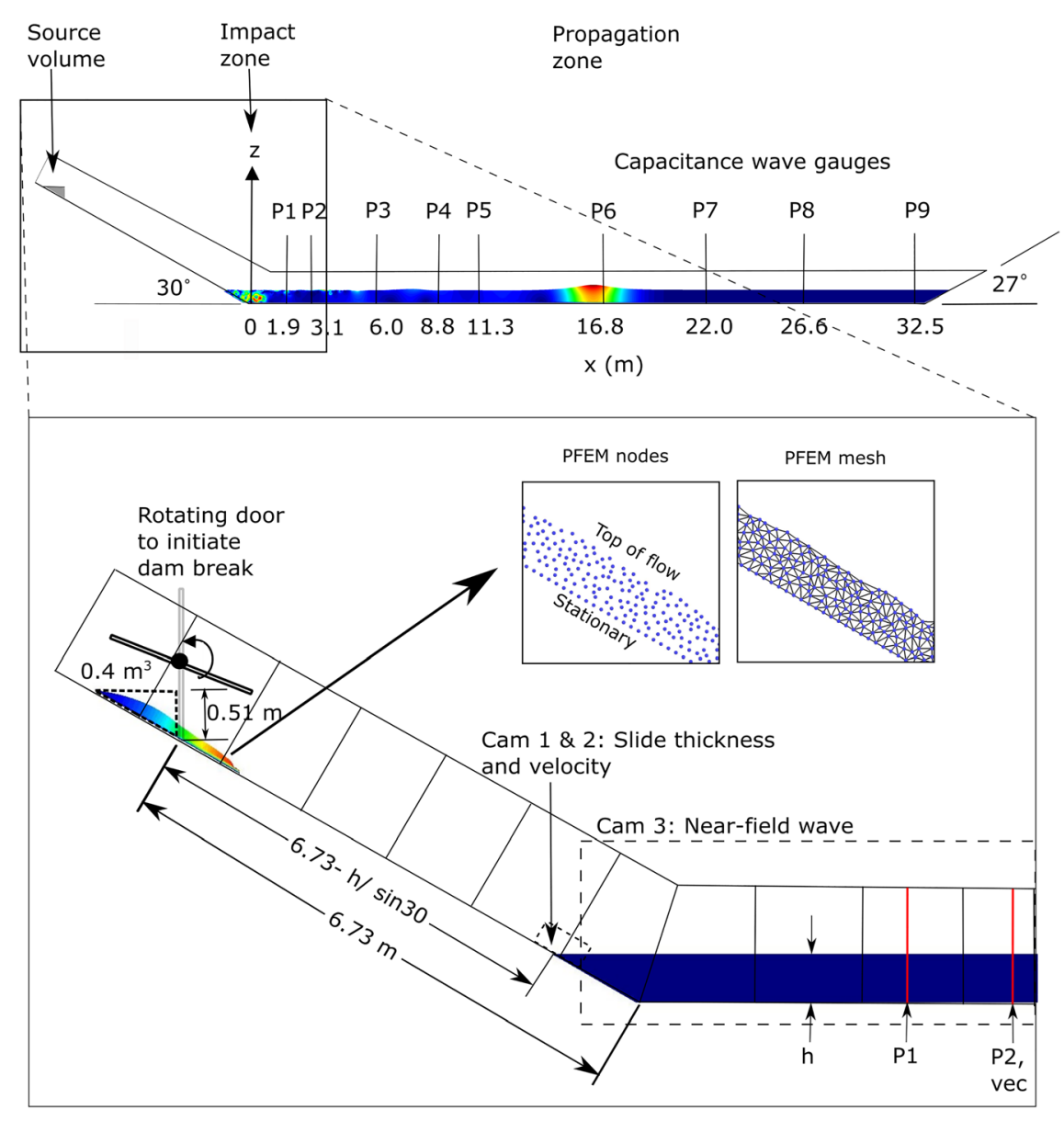

Figure 2. Setup of the landslide wave flume for the experimental and numerical domains.

The PFEM is a Lagrangian numerical technique that combines the Finite Element Method (FEM) with an efficient remeshing algorithm to solve large deformation problems. The method is commonly used in fluid-structure interaction problems involving large free surface motions and splashing waves (Idelsohn et al., 2004; Oñate et al., 2004; Oñate et al., 2008). PFEM has been successfully used to simulate the propagation of regular non-breaking waves in a flume (Oliveira et al., 2017) and has also shown promise in accurately simulating landslide events (e.g., Zhang et al., 2015; Cremonesi et al., 2017) and their effects on reservoirs (Salazar et al., 2016). In the study by Cremonesi et al. (2011), the potential of PFEM to simulate waves is demonstrated by simulation of two cases including a submerged rigid wedge sliding into water along an inclined plane and a landslide formed by granular material sliding into a channel with water. Landslide waves were also simulated by Salazar et al. (2016), finding that PFEM is a useful tool for analyzing landslide events despite the complexity and uncertainty of the mechanics of the sliding material. Recently, Zhang et al. (2019) used a higher-order PFEM to simulate the impact of submarine landslides on offshore infrastructure. These studies demonstrate the potential of PFEM for simulating landslide waves and provide comparison of the model results with some observations at wave probes, albeit with limited data for validation.

Recently, additional experimental data sets have become available to permit increasingly quantitative validation of numerical model outcomes for landslide-generated waves. In particular, large-scale flume experiments conducted by Bullard, Mulligan, Carreira, and Take (2019) and Bullard, Mulligan, \& Take (2019) using water as the slide material have created a data set of the behavior of highly mobile slides prior to impact with the reservoir, during impact, and as the resulting wave propagates to the far field. The use of water as the sliding material removes uncertainty associated with the rheological behavior of the slide, permitting the validation exercise to focus solely on the ability of the numerical model to quantitatively 
(a)

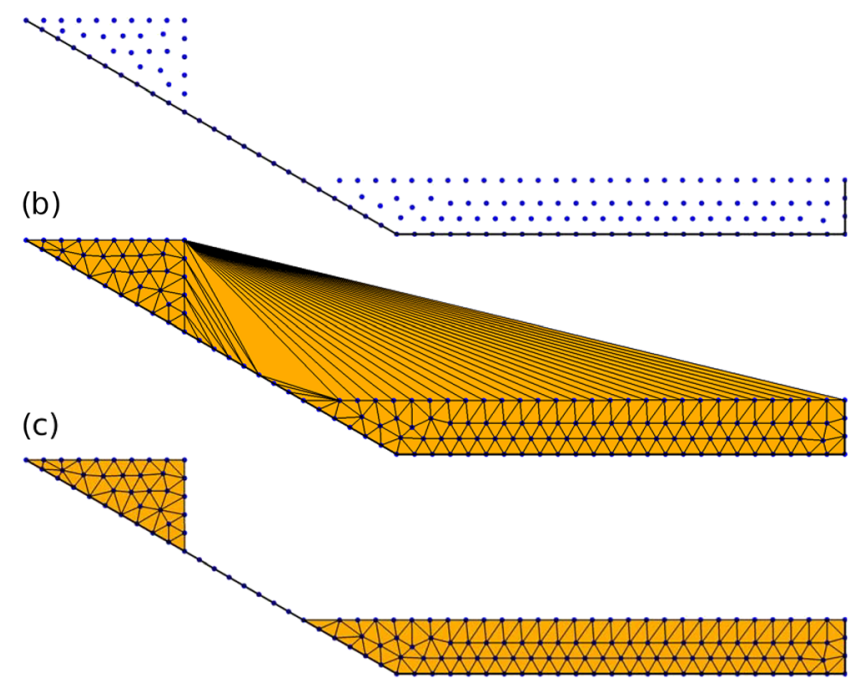

Figure 3. Illustrations indicating the basic steps of the PFEM remeshing algorithm applied to landslide-generated tsunami: (a) the elements of the previous mesh are erased, and only nodal information is retained;

(b) Delaunay triangulation is performed over the cloud of nodal points; and

(c) the Alpha Shape method is applied to the updated computational

domain, and the new mesh is ready for the FEM solver. reproduce key aspects of the behavior in the near and far fields particularly relevant to hazard mitigation (e.g., wave shape, amplitude, breaking behavior, wave celerity, and fluid velocity). Furthermore, it must be considered that water represents an upper bound of mobility for the landslide material and presents a situation that is very complex to numerically simulate.

The objective of this study is to assess the performance of the PFEM to simulate the complete landslide-generated wave problem within a single numerical modeling framework. Different from the previously mentioned PFEM works on landslide waves which were mainly focused on the near-field zone, an extended comparison with experimental observations is performed in the present study. This included the entire landslide-generated wave problem, from the landslide motion and impact with water to the wave generation, transformation, and propagation to the far field and the final runup. In the remainder of this paper, we provide a description of the large-scale experiments of Bullard, Mulligan, Carreira, and Take (2019) and Bullard, Mulligan, and Take (2019), the PFEM approach, and model boundary conditions before comparing experimental and model outcomes at each stage of three different cases of landslide-generated waves.

\section{Landslide Wave Experiments}

The Queen's University landslide flume consists of (a) a dam-break release box located at the top of the flume to initiate the slide down a $30^{\circ}$ slope; (b) a $6.73 \mathrm{~m}$ long transparent-side walled flume to permit observation of the thickness and velocity of the sliding mass as it travels toward the reservoir; (c) a $2.1 \mathrm{~m}$ wide and $33.8 \mathrm{~m}$ long horizontal flume to observe impact, momentum transfer, and wave transformation and propagation in the reservoir; and (d) a $27^{\circ}$ runup and return slope. Drawn to scale in Figure 2, this geometry ensures sufficient wave propagation distance to permit the rapidly evolving waves generated in the near field to transform to solitary-like waves in the far field.

Bullard, Mulligan, Carreira, and Take (2019) and Bullard, Mulligan, and Take (2019) used this facility to conduct 41 experiments covering a wide range of source volumes (0.1-0.4 $\mathrm{m}^{3}$ in increments of $\left.0.1 \mathrm{~m}^{3}\right)$ and reservoir depths $(0.15-0.65 \mathrm{~m}$ in increments of $0.05 \mathrm{~m})$. Three specific experiments have been chosen from this data set for detailed quantitative evaluation of the correspondence between PFEM and experimental outcomes. These experiments have been strategically selected for the largest volume case $\left(0.4 \mathrm{~m}^{3}\right)$ to choose a reservoir depth which ensures the wave should break in the near field $(h=0.3 \mathrm{~m})$, the most efficient depth for generating persistent large amplitude waves $(h=0.45 \mathrm{~m})$, and a depth sufficiently large to avoid wave breaking $(h=0.60 \mathrm{~m})$.

The experimental data obtained from these experiments include the slide flow thickness, $s$, and flow velocity, $v_{s}$, measured at a location immediately prior to impact with the reservoir. These data were obtained using threshold segmentation and digital image correlation image analyses, respectively, using images captured through the transparent side wall at $100 \mathrm{~Hz}$ (Proscilica GX1050 camera with a Nikon Nikkor $24 \mathrm{~mm}$ $\mathrm{f} / 2.8 \mathrm{D}$ lens) and of the top surface of the flow at $480 \mathrm{~Hz}$ (Sony RX10M2 with a 24-200 mm f/2.8 lens). The shape of the wave at impact was recorded at $29 \mathrm{~Hz}$ (Canon T5i camera with 18-55 mm lens) with an approximate field of view illustrated in Figure 2 labeled Cam 3.

The locations of sensors for capturing wave behavior in the reservoir are described with respect to an origin defined at the corner of the inclined portion of the slope and the base of the horizontal portion of the flume. The water surface elevation $(\eta)$ was measured at $100 \mathrm{~Hz}$ using nine $0.6 \mathrm{~m}$ long capacitance wave probes (Akamina AWP-24 Wave Height Gauge). These wave probes were located along the flume centerline at stations P1-P9 ( $x=1.9,3.1,6.0,8.8,11.3,16.8,22.0,26.6$, and $32.5 \mathrm{~m})$ from the origin $x=0.0 \mathrm{~m}$ at the base of the landslide slope. An acoustic Doppler current profiler (Nortek Vectrino) was used to measure the fluid velocity at $100 \mathrm{~Hz}$ in four $4 \mathrm{~mm}$ wide bins over the range $z=0.003-0.012 \mathrm{~m}$ from the bottom of the flume, 

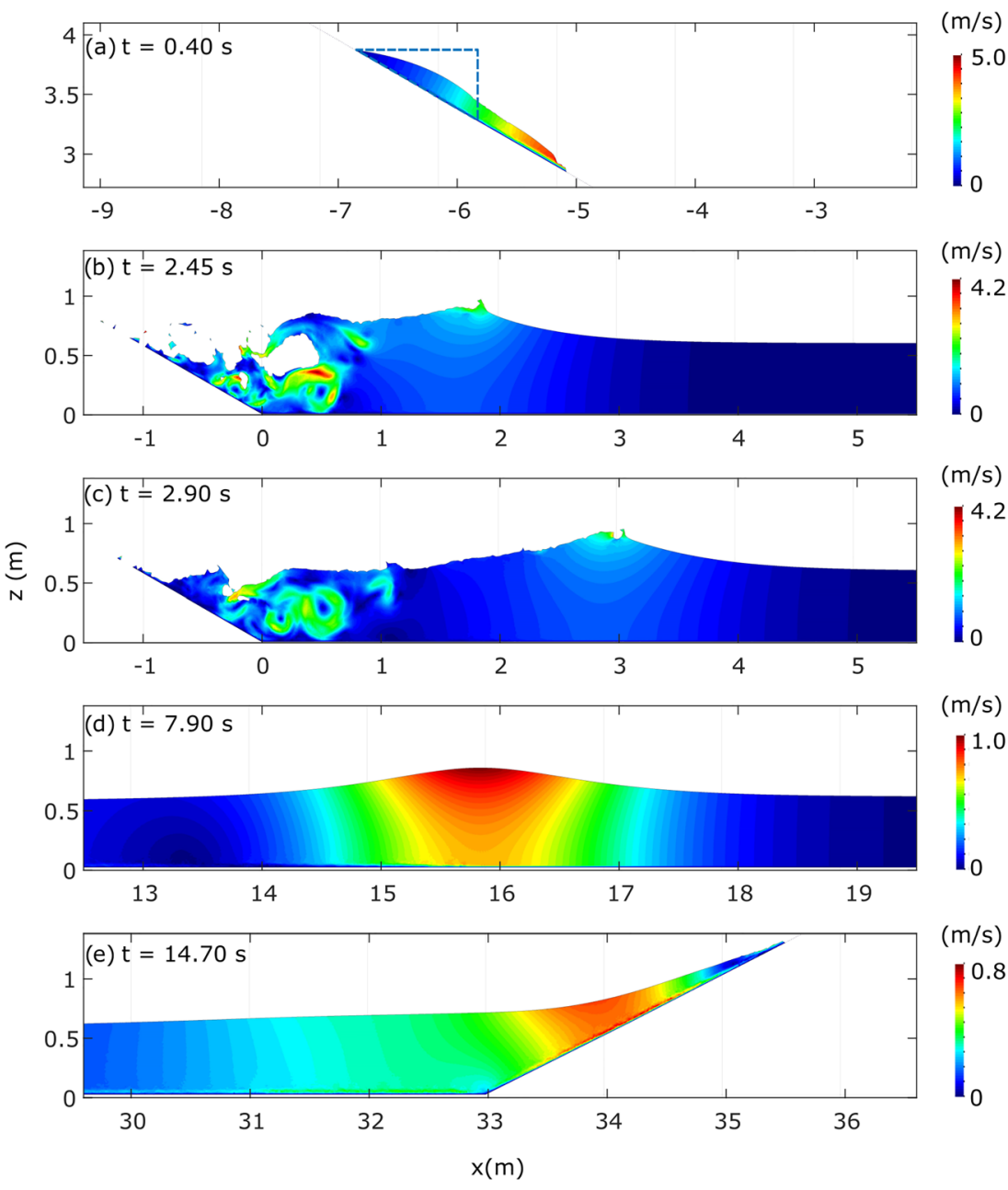

Figure 4. Instantaneous water velocity at different times in the PFEM simulation for the case with $h=0.60 \mathrm{~m}$ : (a) landslide motion; (b) impact wave; (c, d) propagation and shape evolution along the flume; and (e) runup. Note that each plot has a different color scale for the fluid velocity.

located just beyond the maximum distal reach of the $0.4 \mathrm{~m}^{3}$ slides at $x=3.1 \mathrm{~m}$ from the corner of the landslide slope.

This data set therefore enables a direct comparison of model results and experimental outcomes for pre-impact behavior (i.e., slide thickness and velocity), impact behavior (i.e., shape of free surface of water reservoir at various times during impact), and wave transformation and propagation in the reservoir (i.e., time series of wave amplitude recorded along the path of the wave). The complete simulation of these physical phenomena imposes severe constraints on the mesh size and time step of a numerical model and requires a robust computational method with accurate momentum transfer, energy conservation, and free-surface tracking.

\section{Particle Finite Element Method}

\subsection{Model Description}

PFEM is a Lagrangian approach designed to solving large deformation problems. In PFEM, the mesh nodes are treated as material particles and move according to the governing equations of the problem, and the numerical approach is commonly included in the category of particle-based methods. However, different from other particle methods (e.g., SPH, DEM, and LBM), the governing equations are solved with the FEM. In the present case, the Navier-Stokes equations are solved to reproduce the hydrodynamics of the entire water landslide-generated wave problem. The numerical method is based on the implicit stabilized 

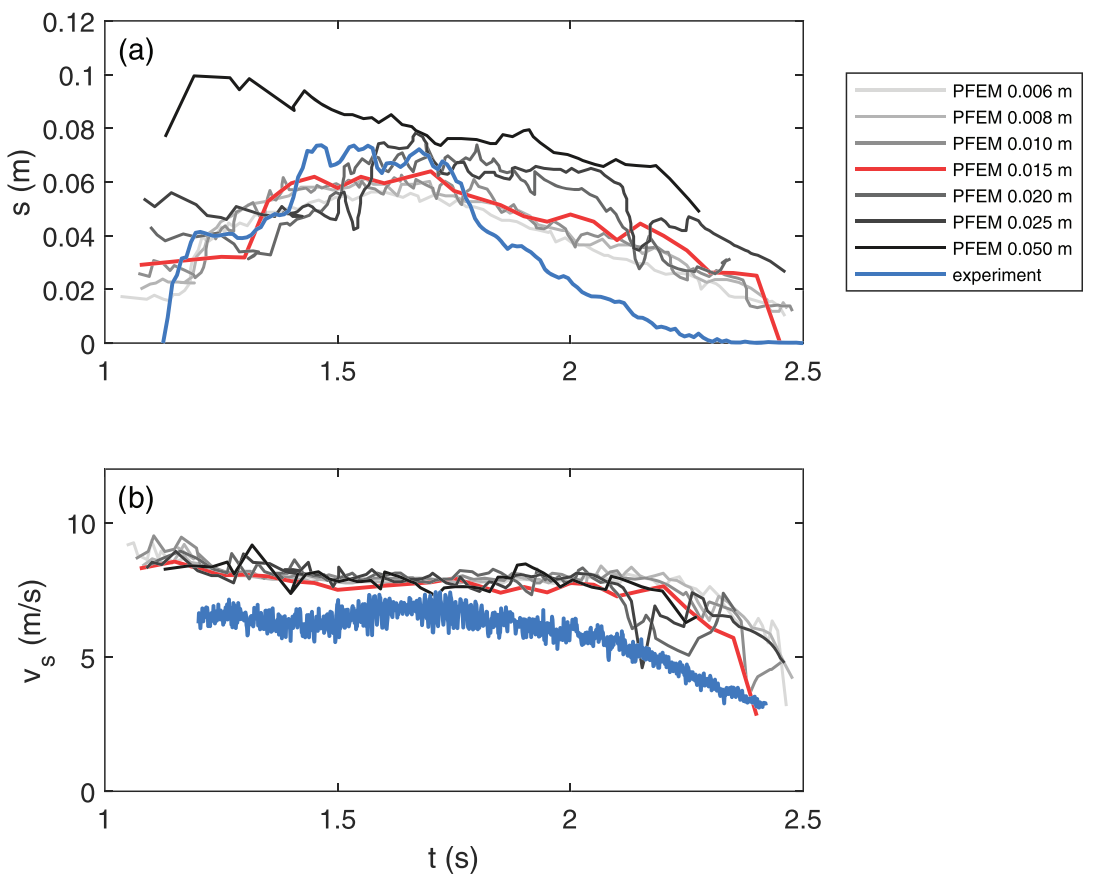

Figure 5. Comparison of observed (Bullard, Mulligan, Carreira, \& Take, 2019) and simulated landslide properties at impact for different PFEM mesh sizes: (a) thickness and (b) velocity. The mesh size used $(0.015 \mathrm{~m})$ is shown in red.

strategy derived and validated for free-surface Newtonian fluids in Oñate et al. (2014). The linear momentum balance and mass conservation equations are solved with an iterative two-step velocitypressure scheme, and linear shape functions are used to implicitly solve for the velocity and pressure fields. Recently, the method has been also applied to non-Newtonian fluids (Franci \& Zhang, 2018) and granular flows (Franci \& Cremonesi, 2019).

As in the original PFEM formulation (Idelsohn et al., 2004), the mesh node positions are continuously updated after each step in the FEM solution. This procedure, when applied to large deformation problems, inevitably leads to excessive distortion of the spatial discretization. The mesh quality is therefore checked at the beginning of each time step in the computation, and if the mesh distortion level exceeds a pre-defined limit, a new mesh is created. This is accomplished in three steps. First, all the elements of the previous distorted mesh are erased as shown in Figure 3a, and the problem information is stored at the nodes. Second, the new mesh is created with the method of Delaunay triangulation (Edelsbrunner \& Tan, 1993) over the cloud of points formed by the nodes of the previous mesh as indicated in Figure 3b. Finally, the new computational domain contours are defined using the Alpha Shape $(\alpha)$ method (Edelsbrunner \& Mücke, 1994). This is completed by performing a geometrical check in which all elements that are excessively distorted are eliminated as shown in Figure 3c. The Alpha Shape check is driven by the parameter $\alpha$, and Franci and Cremonesi (2017) showed that values of $\alpha$ close to 1.25 are recommended to limit volume variation during remeshing. This remeshing procedure makes PFEM capable of modeling complex topological variations such as breaking waves and the separation of fluid from the main fluid domain representing, for example, the effects of splash into air and air entrainment in water. Following other applications of the PFEM framework for waves generated by landslides (Cremonesi et al., 2011; Salazar et al., 2016), a turbulence model is not included. Although this represents a simplification, these effects are secondary with respect to the larger-scale (greater than element size) phenomena, and turbulence models have limitations in 2-D analysis and demand higher additional computational cost.

\subsection{Model Setup}

Material properties are described in the governing equations by the density and viscosity of water $(1,000 \mathrm{~kg} /$ $\mathrm{m}^{3}$ and $0.001 \mathrm{~Pa} \cdot \mathrm{s}$, respectively), and the model domain is constructed in two-dimensions (2-D) where $x$ is the horizontal coordinate and $z$ is the vertical coordinate. The current implementation of the model supports 

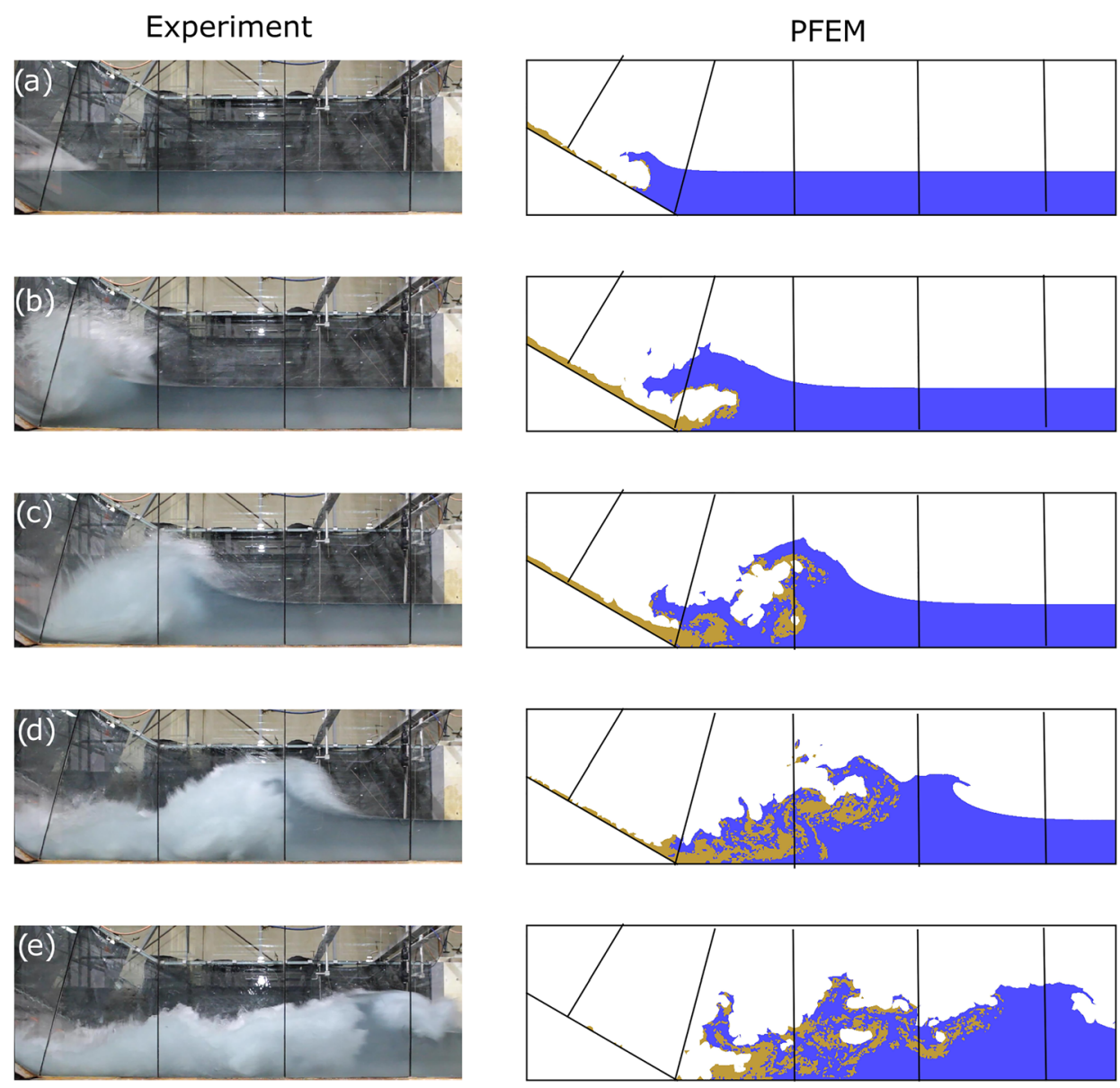

Figure 6. Side-by-side comparison of images from the same time steps in the experiment (left) and output from PFEM (right) for the case of $h=0.30 \mathrm{~m}$. In PFEM the landslide material is shown in gold, and water in the reservoir is shown in blue. The time difference between each frame is $0.3 \mathrm{~s}$.

3-D simulations; however, the 2-D setup has been selected for high accuracy and reasonable computational costs. The initial PFEM mesh is defined corresponding to the experimental setup of Bullard, Mulligan, Carreira, and Take (2019), with $0.4 \mathrm{~m}^{3}$ source volume of water in the release box at the top of the slope above the $33.8 \mathrm{~m}$ long reservoir of water. The rigid base of the flume is modeled with a no-slip condition (e.g., Salazar et al., 2016) defined by regularly spaced nodes that remain stationary during the simulation. Nodes corresponding to the slide mass traveling over this boundary are illustrated in the inset diagram of Figure 2, prior to and following remeshing into triangular elements using the Alpha Shape method. The simulations were conducted with a mesh size of $0.015 \mathrm{~m}$, after sensitivity tests for seven different mesh sizes were conducted, with a fixed time step of $5 \times 10^{-4} \mathrm{~s}$ for a duration of $25 \mathrm{~s}$. This length of simulation is sufficient to capture pre-impact slide behavior, impact, and wave propagation in the $x$ direction to the end of the flume, runup the slope, rundown and reflection, and propagation back toward the impact site. Simulations are completed for three strategically selected water depths in the reservoir $(h=0.30,0.45$, and $0.60 \mathrm{~m}$ ) that correspond to near-field waves that are observed in the experiments to be breaking, at the maximum amplitude, and non-breaking, respectively. Each numerical simulation ran over a duration of 4 days with serial computations performed on a system with an Intel Core i7-4790 processor.

\section{Results}

\subsection{Overview of Results}

An overview of simulation results for the complete landslide-generated wave problem is illustrated as snapshots of horizontal $(u)$ velocity contours for each stage of model behavior for the $h=0.60 \mathrm{~m}$ test case in 
Experiment
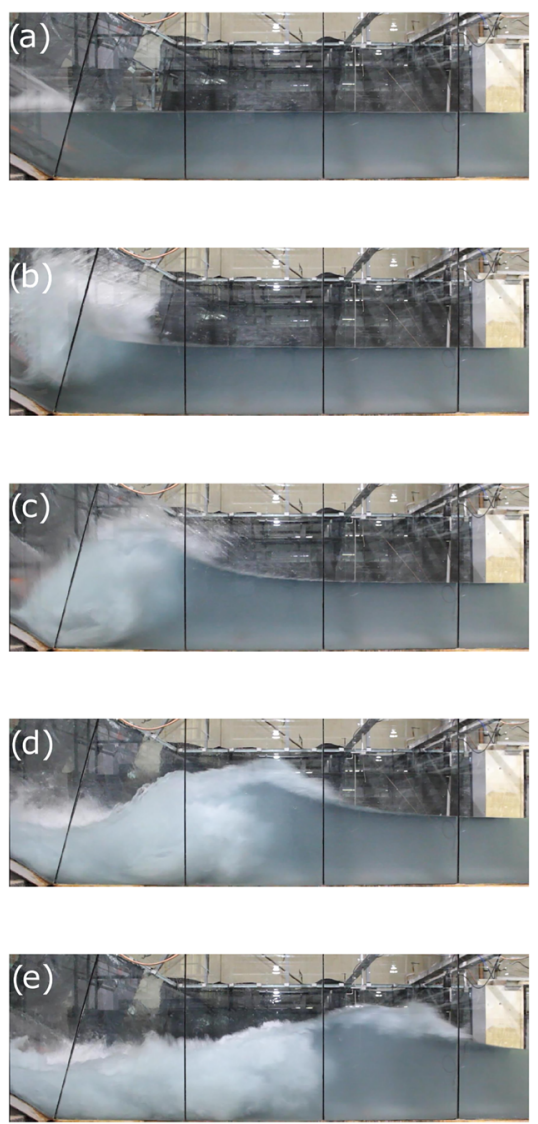
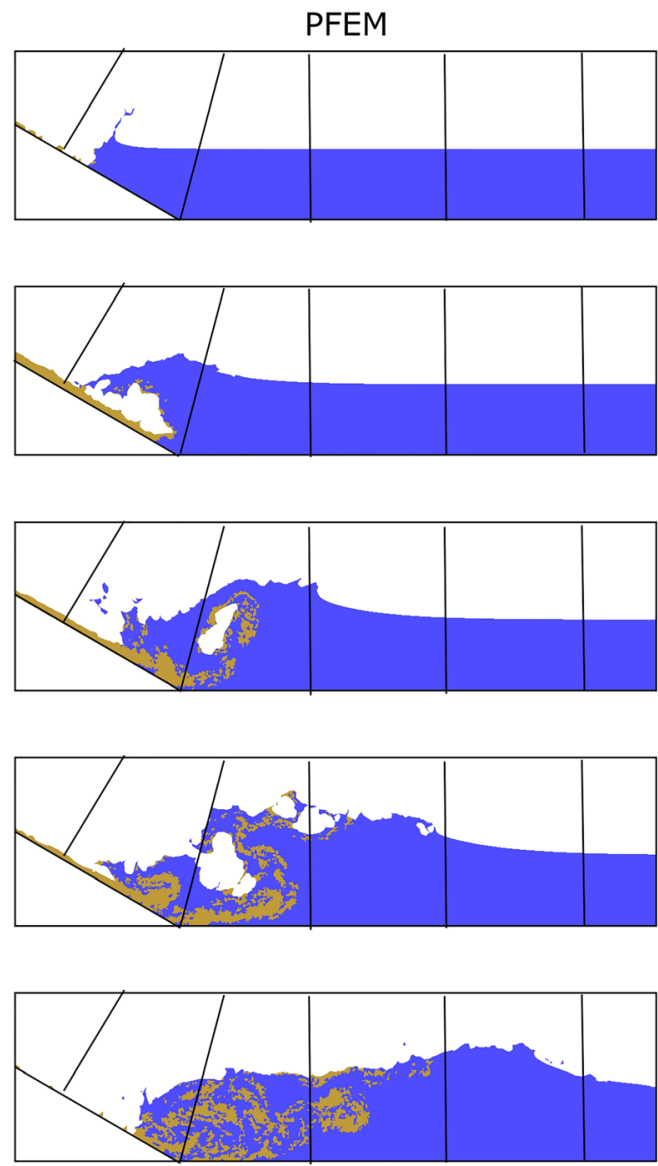

Figure 7. Side-by-side comparison of images from the same time steps in the experiment (left) and output from PFEM (right) for the case of $h=0.45 \mathrm{~m}$. In PFEM the landslide material is shown in gold, and water in the reservoir is shown in blue. The time difference between each frame is $0.3 \mathrm{~s}$.

Figure 4. As an example of pre-impact behavior at $0.4 \mathrm{~s}$ after dam break, the slide material emerges from the release box and begins its journey down the $30^{\circ}$ incline toward the reservoir (Figure $4 \mathrm{a}$ ). Upon impact, the free surface of the fluid is highly dynamic and complex as the slide and reservoir materials mix, elements are ejected from the main body of the reservoir as splash, and the resulting transfer of momentum creates a wave. This is captured in Figure $4 \mathrm{~b}$ for the time of arrival of the wave at the first wave probe $(x=1.9 \mathrm{~m})$. Following impact, the velocity of the wave is greater than the submerged slide material, and the wave propagates out from the near field. Figure $4 \mathrm{c}$ represents the time at which the wave passes past the location of the second wave probe (P2) and the Vectrino sensor $(x=3.1 \mathrm{~m})$. As the wave propagates further into the far field, the amplitude of the wave is observed to reduce, and the shape of the wave tends toward a smooth solitary wave with a longer wave length (Figure $4 \mathrm{~d}$ ). At this time instant the maximum horizontal component of the orbital velocity is approximately $1.0 \mathrm{~m} / \mathrm{s}$. Finally, the runup behavior of the solitary-like wave is shown in Figure 4e, in which the simulation models a thin flow propagating up the return slope until reaching a runup elevation of $1.3 \mathrm{~m}$ at $14.7 \mathrm{~s}$ after dam break. It is clear from this overview that the PFEM simulation qualitatively captures many of the features of the detailed experimental case study. In the next sections, we use this data set to perform a direct quantitative comparison of PFEM and experimental outcomes at each stage at which data are available.

\subsection{Pre-Impact}

The pre-impact stage of the slide-generated wave mechanism is defined herein as the point of triggering of dam break until the instant before reservoir impact. This stage of the model involves the transformation of 

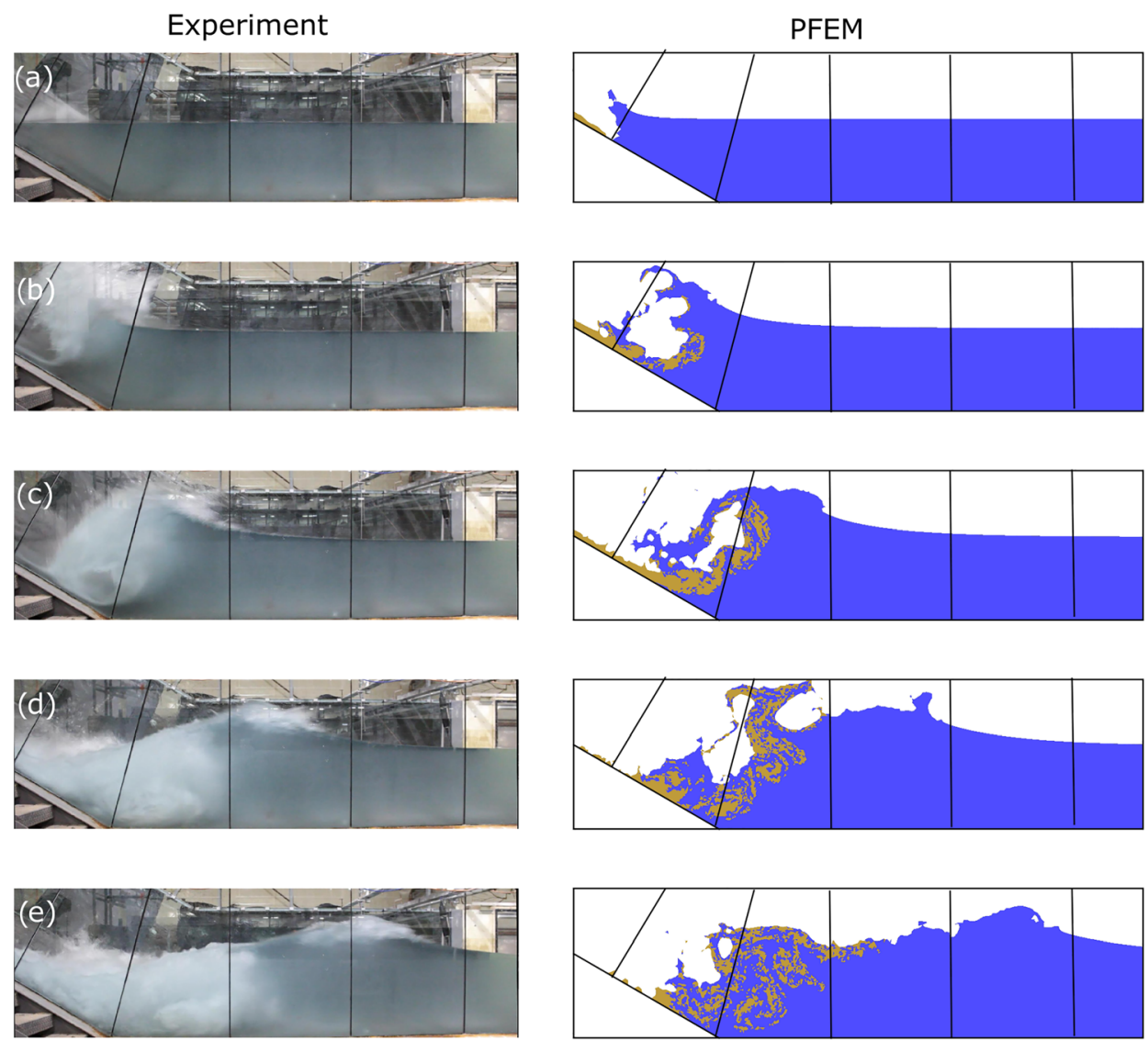

Figure 8. Side-by-side comparison of images from the same time steps in the experiment (left) and output from PFEM (right) for the case of $h=0.60 \mathrm{~m}$. In PFEM the landslide material is shown in gold, and water in the reservoir is shown in blue. The time difference between each frame is $0.3 \mathrm{~s}$.

the initially stationary triangular source volume into a thin, fast, flow of material down slope and represents a particularly challenging scenario for model stability. This stage of the process was therefore chosen to test numerical convergence, with seven different mesh sizes $(0.006,0.008,0.010,0.015,0.020,0.025$, and $0.050 \mathrm{~m})$ tested to ensure that the number of elements was sufficient to simulate the very thin and fast moving slide. The coarsest mesh is composed of 18,618 triangular elements, and the finest mesh has 1,315,900 elements, where the number of elements is the total in both the slide source and the reservoir. The observed slide thickness and velocity are compared with simulation results in Figure 5 for all mesh sizes. Both experimental and numerical results are taken at a horizontal distance of $1.0 \mathrm{~m}$ from the base of the reservoir. It is remarkable that the water landslide prior to the impact reaches a height of less than $0.1 \mathrm{~m}$ and a velocity magnitude greater than $6 \mathrm{~m} / \mathrm{s}$. This situation is particularly complex to model numerically as it requires both a reduced mesh size and small time step for an accurate solution. The results show that the mesh size has a reduced effect on the slide velocity; however, for the coarsest meshes the thickness of the slide increases with the mesh size, and the largest mesh of $0.050 \mathrm{~m}$ results in unreasonable thickness compared to the observations. These results indicate that the simulations are generally consistent with experimental observations, with the simulations biased to slightly faster flows than observed in the experiment. Broadly speaking, these differences are deemed to be sufficiently minor to allow comparisons of experimental observations and simulations of landslide impact and wave propagation. Since the mesh with $0.015 \mathrm{~m}$ mean element size produced results that are in agreement with the observations, achieved numerical convergence, and was computationally faster than smaller sizes, it was selected for the full landslide wave simulations. For this element size, the initial mesh is composed of 213,451 triangular elements and 108,239 nodes, and any discrepancy between the observed and predicted slide thickness is typically less the size of the finite elements in the mesh. 

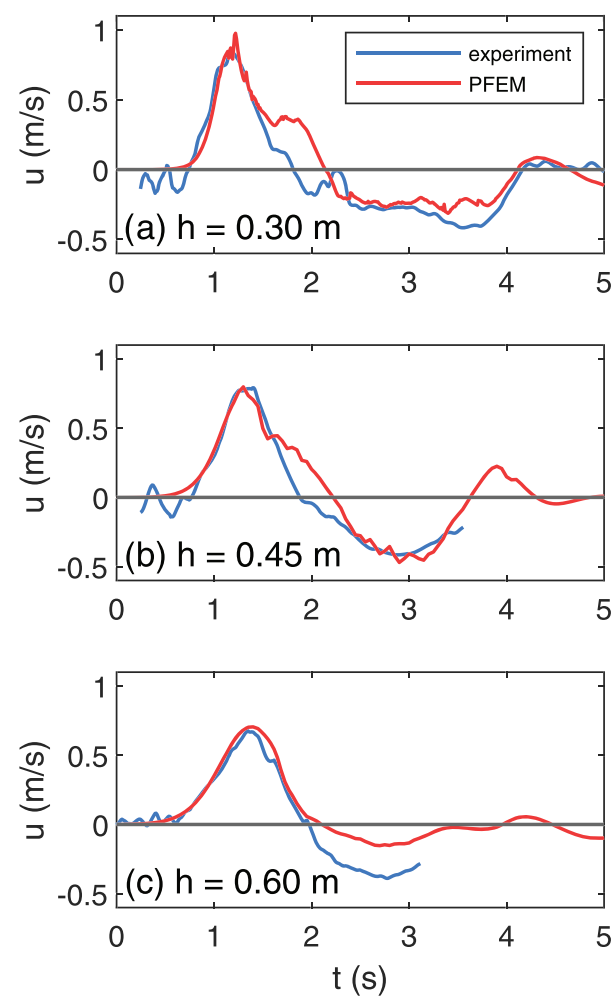

Figure 9. Comparison of the observed near-bed fluid velocity in the reservoir for different water depths at the Vectrino probe location (Bullard, Mulligan, Carreira, \& Take, 2019) with PFEM results.

\subsection{Impact}

For the sake of comparison of PFEM simulations and experimental outcomes, the impact stage of the given slide is defined as the first $1.2 \mathrm{~s}$ after the arrival of the slide material at the elevation of the still water depth in the reservoir. Side-by-side comparisons of the impact process are presented for the three selected cases that correspond to near-field waves that are observed in the experiments to be breaking, at the maximum amplitude, and non-breaking in Figures 6, 7, and 8, respectively. In each comparison, images of the experiment and simulation results are shown at five instants separated by $0.3 \mathrm{~s}$ during the process of impact. Rather than present the PFEM results as velocity contours, in this comparison different colors are given to the slide material (gold) and the water reservoir (blue) to permit an assessment of the degree of mixing in comparison with the white regions where mesh elements are absent and that represent a plume of entrained bubbles in the experiment. In efforts to help provide a visual comparison of PFEM results to camera images capturing the impact within the experiment, the joints between the tempered glass side panels of the flume have been superimposed in the PFEM results.

For the shallowest water depth ( $h=0.30 \mathrm{~m}$, Figure 6$)$, the thin slide material is illustrated impacting the reservoir (Figure 6a), creating an impact crater (Figure 6b), flowing along the bottom of the flume before recirculating upward in a rotating flow around an encased air cavity (Figure 6d). The top surface of the wave at this instant is seen to break in both the experiment and the simulation. A comparison of the impact for the depth of maximum wave amplitude $(h=0.45 \mathrm{~m})$ is presented in Figure 7. Good visual agreement between experiment and PFEM are observed, with the model correctly simulating a much lower degree of wave breaking at this depth. The third test case for impact is for the deep water case $(h=0.60 \mathrm{~m})$ presented in Figure 8. Of particular note is Figure 8c, which illustrates that this depth is sufficiently deep for the recirculating flow to begin to rotate upward prior to reaching the base of the flume (i.e., cf. Figure 8c to Figure $6 \mathrm{c}$, and Figure 7c). This implies that this case is approaching the depth required for deep water conditions (i.e., the depth of the reservoir not influencing the amplitude in the near field). These numerical results indicate that the rotating eddies have a length scale on the order of the flume depth and although they were not directly measured, camera images indicate very turbulent conditions similar to the results of the PFEM simulations (e.g., Figures 8c-8e).

In each of these comparisons, the PFEM simulations are observed to adequately capture the major characteristics of the momentum transfer process and the resulting amplitude and shape of the nonlinear wave in the near field. At $x$-coordinates significantly behind the leading wave, the simulations do exaggerate the splash at the site of impact. This model error could be related to the 2-D $(x, z)$ simulations, even in comparison to the flume experiments, with overestimation of the wave splash due to the fact that three-dimensional (3-D) effects of breaking and turbulence are neglected. This would dissipate some wave energy in the transversal $(y)$ direction and possibly reduce splash in the $x$ and $z$ directions. Discrepancies related to simulating the splash could also be due to the element size and remeshing algorithm, since true splash composed of many small water droplets ejected into the air would not be simulated.

The 2-D mesh in the present study has a very large number of elements, and a very small time step is required to achieve the accurate computations. Without including further simplifications, a 3-D mesh with the same mean element size would be composed of tens of millions of tetrahedral elements and would therefore be prohibitively expensive. It is noted that site geometry is highly important and in many field cases the three-dimensionality is an important aspect of the problem (e.g., McFall \& Fritz, 2016; Mohammed \& Fritz, 2012) particularly in regard to diffraction and radial spreading of energy (e.g., Ruffini et al., 2019) to characterize tsunami hazards on shorelines. With continuous advances in computing power, 3-D 

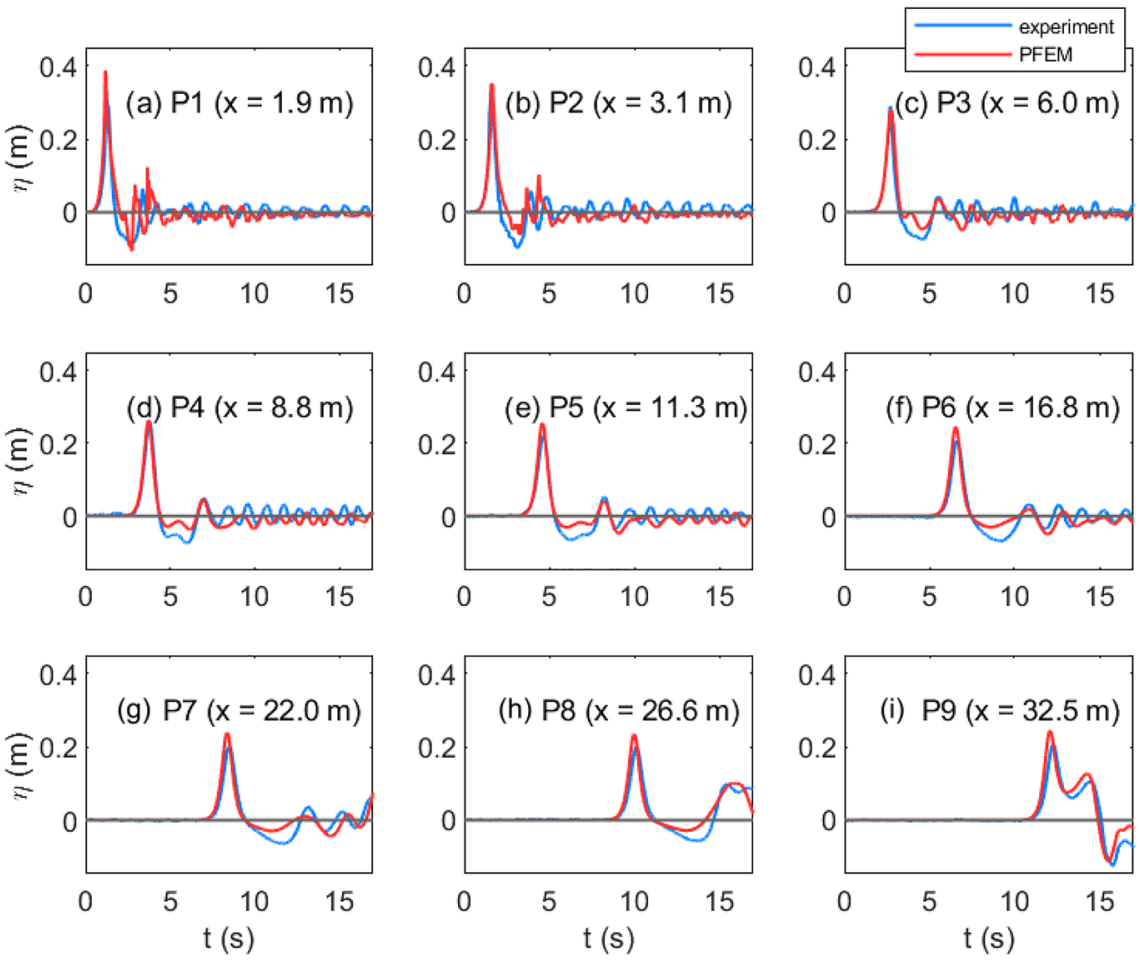

Figure 10. Comparison of the water surface elevation time series measurements at the nine wave probe locations for the case of $h=0.60 \mathrm{~m}$ (Bullard, Mulligan, Carreira, \& Take, 2019) with PFEM results.

simulations of landslide-generated waves at larger scales are possible in the near future. However, the near-field process of wave generation can be examined as a 2-D problem to obtain insight into how the slide interacts with water at impact (e.g., Fritz et al., 2004) and conservatively determine near-field wave parameters. For example, Heller and Spinneken (2015) describe how for large slides, relative to the water depth, the 3-D wave heights in the slide impact zone can be as large as in 2-D. Since the focus of the landslide tsunami hazard assessments is on the first-order importance of the 2-D phenomena that control the amplitude and shape of the largest wave, we consider the results of the 2-D simulations to be in very good agreement with the experimental observations.

\subsection{Wave Propagation and Evolution}

After impact, the wave propagates and transforms along the flume, and the PFEM results are compared to laboratory measurements in Figures 9-13. The mean horizontal component of the fluid velocity was measured near the bed $(z=0.01 \mathrm{~m})$ at $x=3.1 \mathrm{~m}$, adjacent to wave probe P2. The observations are shown together with the simulated results at this location in Figure 9. The observations and modeled time series are in very close agreement in each case, and the model accurately captures the timing and peak orbital velocity of the leading wave crest. The peak velocity decreases from approximately $u=0.9 \mathrm{~m} / \mathrm{s}$ for the shallowest reservoir depth to $u=0.7 \mathrm{~m} / \mathrm{s}$ for the deepest reservoir, as a function of both the differences in wave evolution and distance from the free surface. Following the positive velocity associated with the wave crest, the observed and simulated negative orbital velocity in the wave trough is also in general agreement. The model results for velocity are also shown in Figure 4 for $h=0.60 \mathrm{~m}$ at selected times during wave propagation.

The model results are also in general agreement with the free surface elevation $(\eta)$ measurements of the rapidly evolving waves. Time series at the wave probe locations are shown in Figure 10 for the nine wave probes (P1-P9) in the case with $h=0.60 \mathrm{~m}$, capturing the arrival time and temporal variability of the wave at each location. In this case, the wave amplitude change from frequency dispersion is evident as indicated by the reduction in the surface elevation at the peak of the wave crest along the flume. It is noted that mass conservation is an important issue and remeshing inevitably induces volume variation in PFEM; 

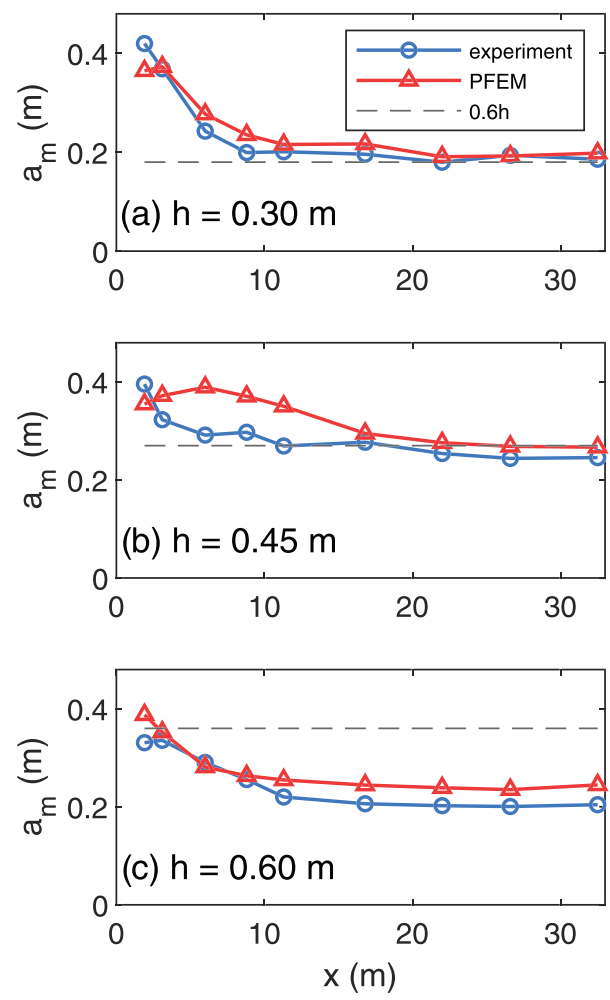

Figure 11. Comparison of the maximum wave amplitude at each wave probe location along the flume for different water depths (Bullard, Mulligan, Carreira, \& Take, 2019) with PFEM results. The dashed line indicates the theoretical wave breaking limit in each case. however, the effect is kept small by a fine mesh and properly selecting the Alpha Shape parameter (Franci \& Cremonesi, 2017). Differences between the observations and the model results are likely related to the different splash and defining the water surface in the near field (e.g., at $x=1.9 \mathrm{~m}$; Figure 10a) as the agreement between measurements and simulations improves with distance from the generation zone (e.g., $x=8.8 \mathrm{~m}$, Figure 10d). The celerity is also evident in Figure 10 by the different wave arrival times at the probes. The arrival time at P9 at the far end of the flume ( $x=32.5 \mathrm{~m}$ ) is $12.1 \mathrm{~s}$ from the point of impact $(t=0)$ in this depth, and the average celerity of $c=2.7 \mathrm{~m} / \mathrm{s}$ is consistent with the shallow water solitary wave speed, $c=\sqrt{g\left(a_{m}+h\right)}$. Any errors are compounded with distance, and the time difference between observations and PFEM at P9 is $0.17 \mathrm{~s}$ ( $1 \%$ of the total time) for this case $(h=0.60 \mathrm{~m})$, and time differences are also small for the other cases with $0.06 \mathrm{~s}(h=0.45 \mathrm{~m})$ and $0.41 \mathrm{~s}$ $(h=0.30 \mathrm{~m})$. The water surface elevation time series for the cases with $h=0.30 \mathrm{~m}$ and $h=0.45 \mathrm{~m}$ are provided as Figures S1 and $\mathrm{S} 2$ in the supporting information.

The peak value of $\eta(t)$ is used to define the maximum wave amplitude $\left(a_{m}\right)$, and the values of $a_{m}$ are shown at all nine wave probes for all three PFEM simulations in Figure 11. For the case of wave breaking in Figure 11a, the model-data agreement is very close. The wave breaking relationship of $a_{m} / h=0.6$ as described by Bullard, Mulligan, Carreira, and Take (2019) is closely adhered to in the model suggesting that PFEM is accurately simulating the bulk effects of turbulent wave breaking. The maximum stable wave amplitude for this source volume is shown in Figure 11b. For this case, where some wave breaking also occurs in the near field, the model does not agree with the observations. However, once the wave evolves over a distance of approximately $17 \mathrm{~m}$ and the stable amplitude is reached, the model and observations match. For the non-breaking case shown in Figure 11c, very similar values of $a_{m}$ occur at each wave probe. These non-breaking waves also attenuate in amplitude with distance from the source region; however, this is related to the evolution of wave shape (Bullard, Mulligan, \& Take, 2019) since the asymmetry tends toward zero as the wave form changes to match a solitary wave. In agreement with previous studies of non-breaking impulse waves (Fritz et al., 2004; Zweifel et al., 2006), the decay of wave amplitude is accompanied by the increase of wave length with the propagation distance, and this is governed by the combined effects of frequency dispersion and viscous dissipation.

To further quantify the goodness of fit between the data and model results at all wave probes, a scatter plot is shown in Figure 12. Here, the relative maximum wave amplitude $\left(a_{m} / h\right)$ is shown, and this non-dimensional variable allows the cases with different water depths to be combined. The overall agreement, indicated by generally small deviation from the 1:1 line, suggests that the PFEM results are reasonably accurate over a wide range of conditions at near-field and far-field sites where the waves are breaking or not breaking.

The PFEM results for the evolution of $a_{m}$ along the flume are shown in Figure 13 for each reservoir depth $h$. In addition to the three experiments that correspond to the simulated cases, all 11 experiments with the same source volume of $V=0.4 \mathrm{~m}^{3}$ are shown, and these cover the range $h=0.15-0.65 \mathrm{~m}$. In the near field at P1 (Figure 13a), the maximum wave amplitude is independent of
Figure 12. Scatter plot for measured data (Bullard, Mulligan, Carreira, \& Take, 2019) and simulated relative maximum wave amplitude $\left(a_{m} / h\right)$ for all wave probe locations and each reservoir depth. The solid 1:1 line indicates perfect agreement, and the breaking index $\left(a_{m} / h=0.6\right)$ is shown by the dashed lines. 

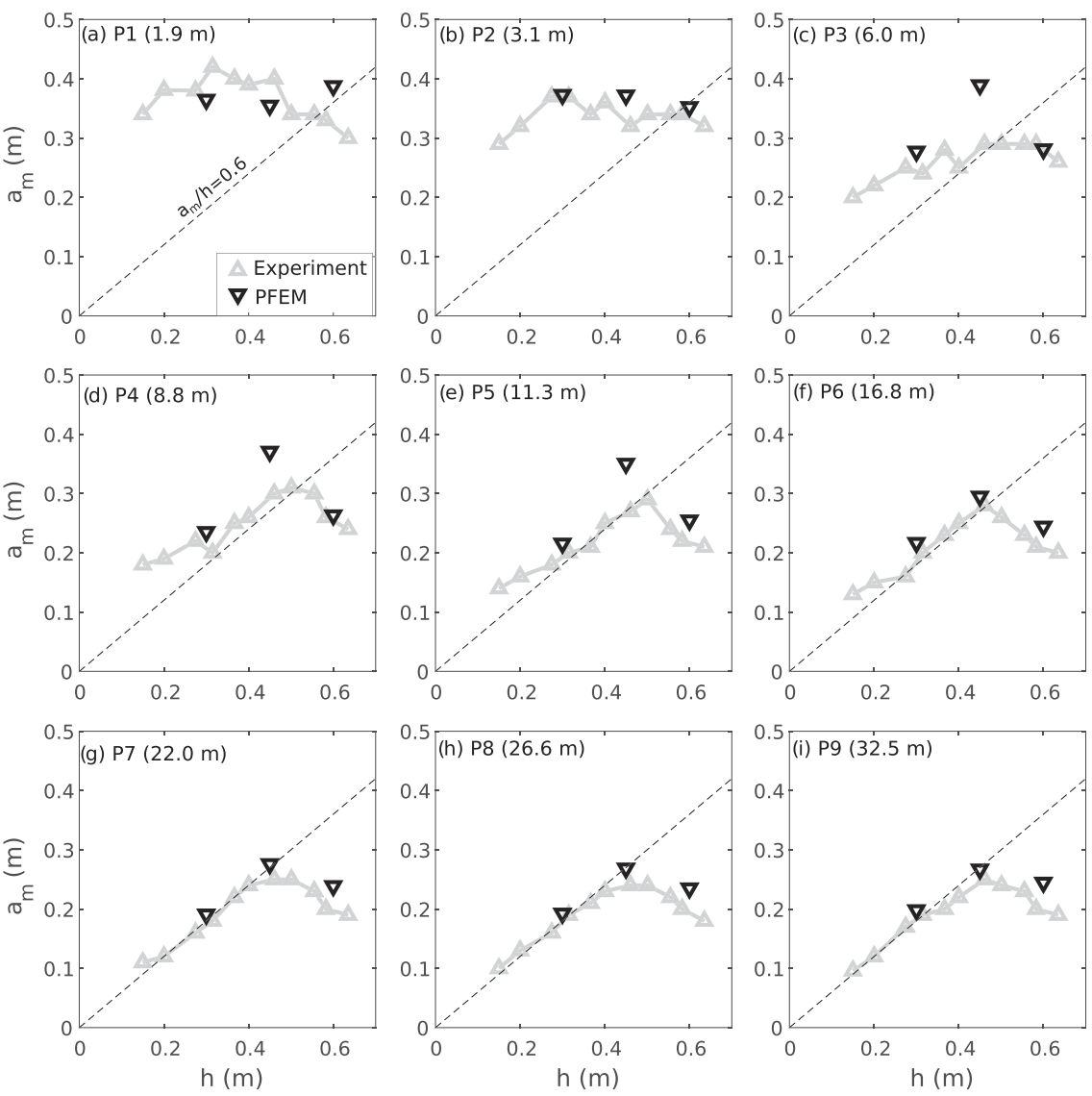

Figure 13. Comparison of the maximum wave amplitude at each wave probe for each of the 11 different water depths in the experiments of Bullard, Mulligan, Carreira, and Take (2019) and the PFEM simulation results. The dashed line indicates the breaking relationship.

water depth in the reservoir. However, these waves rapidly break. The breaking waves are indicated by points that lie above the $a_{m} / h=0.6$ line, and the amplitude of these waves reduces at successive wave probes to a value that lies on the line (e.g., P6, Figure 13f) in both the observations and the model results.

The wave amplitude is not the only wave property that changes as the waves propagate along the flume. The effect of wave breaking and dispersion also significantly change the shape of the waves with distance, and the experimental results for wave shape are quantified by the asymmetry of the wave probe time series in Bullard, Mulligan, and Take (2019). The numerical results of the PFEM now permit an investigation of the water surface profile in space along the flume. As shown in Figure 14, the spatial near-field shape (at $x=3 \mathrm{~m}$ ) is compared to the far-field shape (at $x=30 \mathrm{~m}$ ), and there is a major change that is different for each reservoir depth. For $h=0.30 \mathrm{~m}$ the near-field wave is a breaking bore with an irregular shape (Figure 14a). For $h=0.45 \mathrm{~m}$ the near-field shape is steeper on the leading side and therefore has negative asymmetry (Figure 14b), with a combination of breaking and dispersion that influence the amplitude and shape. For $h=0.60 \mathrm{~m}$ the near-field shape is flatter on the leading side and has positive asymmetry (Figure 14c). This wave is not breaking, and the attenuation of amplitude due to dispersion results in widening of the wave length on the trailing side and therefore conservation of volume in the wave. In agreement with previous studies, different near-field wave types can be generated depending on the impact characteristics (e.g., Heller \& Hager, 2011). In all three cases PFEM predicts that with distance the wave shape approaches that of a solitary wave, and the far-field wave shape is in remarkably close agreement with the solitary wave equation (Bullard, Mulligan, \& Take, 2019; Mei, 1989) for each water depth and wave amplitude. The effects of far-field dispersion are therefore accurate since the wave amplitude and shape are both correctly 

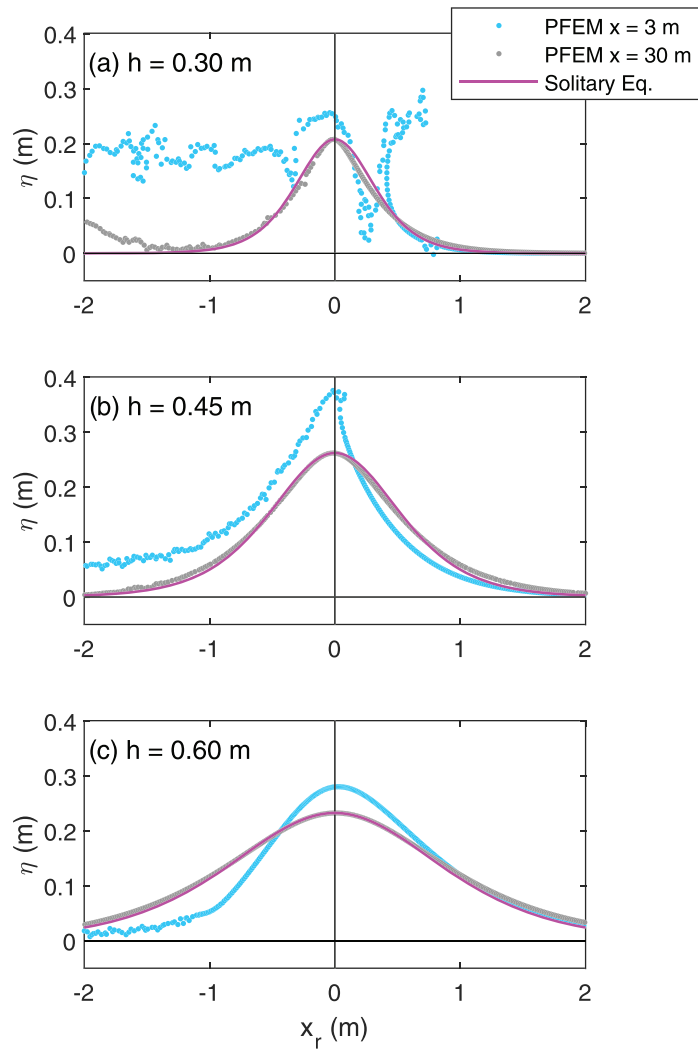

Figure 14. Near-field $(x=3 \mathrm{~m})$ and far-field $(x=30 \mathrm{~m})$ comparison of the wave shape results from PFEM. The water surface elevation predicted by the solitary wave equation (given by eq. 5 in Bullard, Mulligan, \& Take, 2019) for each water depth and maximum wave amplitude at $x=30 \mathrm{~m}$ is shown. Note that in (a), the PFEM results at $x=3 \mathrm{~m}$ correspond to the irregularly shaped near-field breaking wave as shown in Figure 6e. predicted by PFEM. Overall, the results suggest that PFEM is able to accurately simulate the slide momentum at impact, generate the correct near-field wave properties, and predict breaking and transformation as the tsunami propagate into the far field.

\subsection{Runup}

At the end of the flume, PFEM simulates runup on the slope as indicated in Figure 4e for $h=0.60 \mathrm{~m}$. For the reservoir depths of $h=0.30$, 045 , and $0.60 \mathrm{~m}$, the predicted runup elevations are $0.63,0.81$, and $0.71 \mathrm{~m}$ above the still water level in each case, respectively. These values are a function of the water depth, incident wave amplitude and far-field solitary wave shape, and slope angle. It is noted that runup measurements were planned as part of the Bullard, Mulligan, Carreira, and Take (2019) and Bullard, Mulligan, and Take (2019) study, however were not collected due to the failure of the runup probe.

A predictive equation for impulse wave runup on steep slopes has recently been developed by Evers and Boes (2019). This relationship (their eq. 10) is for non-breaking waves and is dependent on the incident wave amplitude, still water depth, and slope angle. In the absence of experimental measurements of runup, this equation has been implemented and compared with the runup results from the PFEM simulations. The results are shown in Figure 15 and indicate relatively close agreement; however, we note that several of these cases have $a_{m} / h \geq 0.6$ and differences may be due to waves that are breaking during runup, introducing some energy dissipation in the PFEM. This suggests that new research should be conducted to target and develop a predictive equation for runup from landslidegenerated waves that are breaking. It is therefore recommended that further experimental results be obtained to measure runup behavior for far-field cases and for other cases where runup on different slopes occurs in the near field.

\section{Conclusions}

In this study the PFEM, a Lagrangian approach to solving the fluid momentum equations, is applied in two-dimensions to simulate the complete landslide-generated wave problem within a single numerical modeling framework. This problem is numerically challenging and requires fine temporal and spatial resolution to accurately simulate the high velocity, large free surface motions, and splashing waves. Overall, the model results capture the many different physical processes that are inherently coupled including the initiation of slide motion, impact with the reservoir, generation of waves, breaking, propagation, dispersion, and runup.

To assess model performance, the results are compared with data collected by Bullard, Mulligan, Carreira, and Take (2019) in large-scale experiments. Overall, the agreement between observations and model results is remarkable both qualitatively (images of splash, breaking, and mixing) and quantitatively (landslide velocity and thickness, wave time series, maximum wave amplitude, wave speed, and wave shape). The model is initialized with a stationary triangular source volume that is rapidly released down slope and transforms into a thin, fast, flow of material with thickness and velocity that are comparable to observations at impact with the reservoir. The PFEM simulations adequately capture the major characteristics of the momentum transfer process and the resulting amplitude and shape of the nonlinear wave that is generated in the near field. The results provide a complete visualization of the water surface and velocity field and allow for separation of the slide and reservoir materials, aiding in understanding the dynamics of these complex flows. Wave breaking, propagation, and amplitude decay of non-breaking waves due to dispersion are also reasonably accurate in different water depths at near-field and far-field sites. Using PFEM, the evolution of wave shape is now more clearly understood and is in agreement with Bullard, Mulligan, and Take (2019) observations, 
(a)

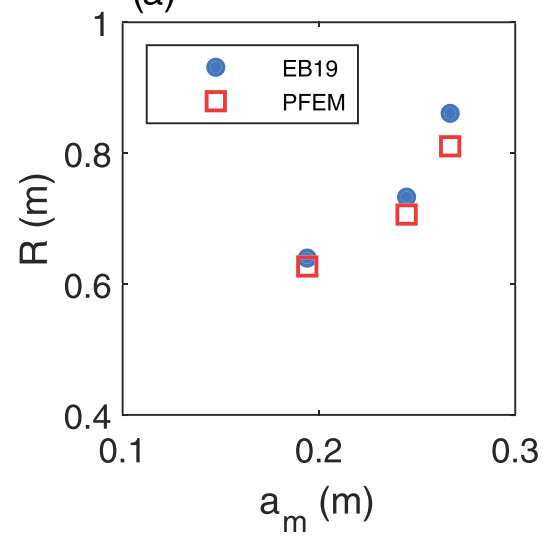

(b)

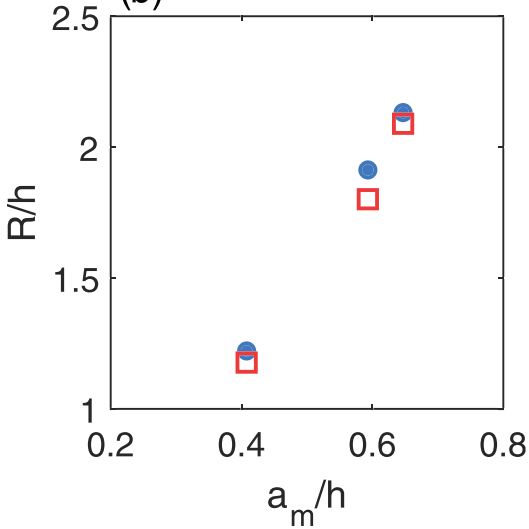

Figure 15. Variability of runup with incident maximum wave amplitude for predictions using EB19 (Evers \& Boes, 2019) and PFEM: (a) dimensional results and (b) dimensionless results, relative to the water depth.

and the waves transform with distance to match the results of the solitary wave equation in the far field. These waves then runup the opposite slope, and future work on far-field impacts such as runup is recommended.

The impulse wave behavior simulated in this paper is applicable to high mobility landslides as the validation experiments of Bullard, Mulligan, Carreira, and Take (2019) and Bullard, Mulligan, and Take (2019) were conducted using water as the sliding material. The advantage of this approach is that the complexity associated with the rheological behavior of the slide is effectively removed from the data set permitting the validation exercise to focus solely on the ability of the numerical model to quantitatively reproduce key aspects of the behavior in the near and far fields particularly relevant to hazard mitigation (e.g., wave shape, amplitude, breaking behavior, wave celerity, and fluid velocity).

Future research could focus on experimental observations and numerical simulations of the runup on different slopes and the application of PFEM in three-dimensions to resolve the highly turbulent velocity fluctuations during wave generation and breaking. The success of PFEM to qualitatively and quantitatively simulate these aspects of the problem indicates that further research incorporating more complex rheological models for landslide behavior (e.g., frictional, Voellmy) is also warranted. This would enable simulations of impulse waves generated by other types of mass flows such as the idealized dry granular flows used most commonly in physical modeling of landslide tsunami (e.g., Miller et al., 2017), and classes of landslides exhibiting more complex rheological behavior with a range of different material properties such as debris flows, lateral spreads, rock slides, and snow avalanches. Overall, the PFEM appears to be a very promising and novel approach to shed light on the complex mechanisms of landslide-generated tsunami generation and propagation.

\section{Data Availability Statement}

The data used in this research are archived in the Department of Civil Engineering at Queen's University and are available in a data repository (accessible at https://doi.org/10.5683/SP2/DREGYG).

\section{References}

Ataie-Ashtiani, B., \& Shobeyri, G. (2008). Numerical simulation of landslide impulsive waves by incompressible smoothed particle hydrodynamics. International Journal for Numerical Methods in Fluids, 56(2), 209-232. https://doi.org/10.1002/fld.1526

Brideau, M. A., Sturzenegger, M., Stead, D., Jaboyedoff, M., Lawrence, M., Roberts, N. J., et al. (2012). Stability analysis of the 2007 Chehalis lake landslide based on long-range terrestrial photogrammetry and airborne LiDAR data. Landslides, 9(1), 75-91. https://doi.org/ 10.1007/s10346-011-0286-4

Bullard, G. K., Mulligan, R. P., Carreira, A., \& Take, W. A. (2019). Experimental analysis of tsunamis generated by the impact of landslides with high mobility. Coastal Engineering, 152, 103538. https://doi.org/10.1016/j.coastaleng.2019.103538

Bullard, G. K., Mulligan, R. P., \& Take, W. A. (2019). An enhanced framework to quantify the shape of impulse waves using asymmetry. Journal of Geophysical Research: Oceans, 124, 652-666. https://doi.org/10.1029/2018JC014167

Cremonesi, M., Ferri, F., \& Perego, U. (2017). A basal slip model for Lagrangian finite element simulations of 3D landslides. International Journal for Numerical and Analytical Methods in Geomechanics, 41(1), 30-53. https://doi.org/10.1002/nag.2544 
Cremonesi, M., Franci, A., \& Perego, U. (2011). A Lagrangian finite element approach for the simulation of water-waves induced by landslides. Computers \& Structures, 89(11-12), 1086-1093. https://doi.org/10.1016/j.compstruc.2010.12.005

Crosta, G. B., Imposimato, S., \& Roddeman, D. (2016). Landslide spreading, impulse water waves and modelling of the Vajont rockslide. Rock Mechanics and Rock Engineering, 49(6), 2413-2436. https://doi.org/10.1007/s00603-015-0769-z

Edelsbrunner, H., \& Mücke, E. P. (1994). Three-dimensional alpha shapes. ACM Transactions on Graphics (TOG), 13(1), 43-72. https://doi. org/10.1145/174462.156635

Edelsbrunner, H., \& Tan, T. S. (1993). An upper bound for conforming Delaunay triangulations. Discrete \& Computational Geometry, 10(2), 197-213. https://doi.org/10.1007/BF02573974

Evers, F. M., \& Boes, R. M. (2019). Impulse wave runup on steep to vertical slopes. Journal of Marine Science and Engineering, 7(1), 8. https://doi.org/10.3390/jmse7010008

Evers, F. M., Hager, W. H., \& Boes, R. M. (2019). Spatial impulse wave generation and propagation. Journal of Waterway, Port, Coastal, and Ocean Engineering, 145(3), 04019011.

Franci, A., \& Cremonesi, M. (2017). On the effect of standard PFEM remeshing on volume conservation in free-surface fluid flow problems. Computational Particle Mechanics, 4(3), 331-343. https://doi.org/10.1007/s40571-016-0124-5

Franci, A., \& Cremonesi, M. (2019). 3D regularized $\mu$ (I)-rheology for granular flows simulation. Journal of Computational Physics, 378, 257-277. https://doi.org/10.1016/j.jcp.2018.11.011

Franci, A., \& Zhang, X. (2018). 3D numerical simulation of free-surface Bingham fluids interacting with structures using the PFEM. Journal of Non-Newtonian Fluid Mechanics, 259, 1-15. https://doi.org/10.1016/j.jnnfm.2018.05.001

Fritz, H. M., Giachetti, T., Anderson, S., and Gauthier, D., 2018. Field survey of the 17 June 2017 landslide generated tsunami in Karrat Fjord, Greenland. In EGU General Assembly Conference Abstracts, Vol. 20 EGU General Assembly, Vienna, Austria, 18345.

Fritz, H. M., Hager, W. H., \& Minor, H. E. (2004). Near field characteristics of landslide generated impulse waves. Journal of Waterway, Port, Coastal, and Ocean Engineering, 130(6), 287-302. https://doi.org/10.1061/(ASCE)0733-950X(2004)130:6(287)

Gauthier, D., Anderson, S. A., Fritz, H. M., \& Giachetti, T. (2018). Karrat Fjord (Greenland) tsunamigenic landslide of 17 June 2017: Initial 3D observations. Landslides, 15(2), 327-332. https://doi.org/10.1007/s10346-017-0926-4

Heller, V., \& Hager, W. H. (2010). Impulse product parameter in landslide generated impulse waves. Journal of Waterway, Port, Coastal, and Ocean Engineering, 136(3), 145-155. https://doi.org/10.1061/(ASCE)WW.1943-5460.0000037

Heller, V., \& Hager, W. H. (2011). Wave types of landslide generated impulse waves. Ocean Engineering, 38(4), 630-640.

Heller, V., \& Spinneken, J. (2015). On the effect of the water body geometry on landslide-tsunamis: Physical insight from laboratory tests and 2D to 3D wave parameter transformation. Coastal Engineering, 104, 113-134. https://doi.org/10.1016/j.coastaleng.2015.06.006

Idelsohn, S. R., Oñate, E., \& Pin, F. D. (2004). The particle finite element method: A powerful tool to solve incompressible flows with free-surfaces and breaking waves. International Journal for Numerical Methods in Engineering, 61(7), 964-989. https://doi.org/10.1002/ nme.1096

Kafle, J., Pokhrel, P. R., Khattri, K. B., Kattel, P., Tuladhar, B. M., \& Pudasaini, S. P. (2016). Landslide-generated tsunami and particle transport in mountain lakes and reservoirs. Annals of Glaciology, 57(71), 232-244. https://doi.org/10.3189/2016AoG71A034

Kim, J., Løvholt, F., Issler, D., \& Forsberg, C. F. (2019). Landslide material control on tsunami genesis-The Storegga slide and tsunami (8,100 years BP). Journal of Geophysical Research: Oceans, 124, 3607-3627. https://doi.org/10.1029/2018JC014893

Lynett, P., \& Liu, P. L. F. (2005). A numerical study of the run-up generated by three-dimensional landslides. Journal of Geophysical Research, 110, C03006. https://doi.org/10.1029/2004JC002443

Ma, G., Kirby, J. T., \& Shi, F. (2013). Numerical simulation of tsunami waves generated by deformable submarine landslides. Ocean Modelling, 69, 146-165. https://doi.org/10.1016/j.ocemod.2013.07.001

McFall, B. C., \& Fritz, H. M. (2016). Physical modelling of tsunamis generated by three dimensional deformable granular landslides on planar and conical island slopes. Proceedings of the Royal Society of London. Series A: Mathematical, Physical and Engineering Sciences, 472(2188), 20160052.

Mei, C. C. (1989). The applied dynamics of ocean surface waves. Singapore: Advanced Series on Ocean Engineering, World Science.

Miller, G. S., Take, W. A., Mulligan, R. P., \& McDougall, S. (2017). Tsunamis generated by long and thin granular landslides in a large flume. Journal of Geophysical Research: Oceans, 122, 1-16. https://doi.org/10.1002/2016JC012177

Mohammed, F., \& Fritz, H. M. (2012). Physical modeling of tsunamis generated by three dimensional deformable granular landslides. Journal of Geophysical Research, 117, C11015. https://doi.org/10.1029/2011JC007850

Mulligan, R. P., \& Take, W. A. (2017). On the transfer of momentum from a granular landslide to a water wave. Coastal Engineering, 125, 16-22. https://doi.org/10.1016/j.coastaleng.2017.04.001

Mulligan, R. P., Take, W. A., \& Bullard, G. K. (2019). Non-hydrostatic modeling of waves generated by landslides with different mobility. Journal of Marine Science and Engineering, 7(8), 266. https://doi.org/10.3390/jmse7080266

Oliveira, T. C. A., Sanchez-Arcilla, A., Gironella, X., \& Madsen, O. S. (2017). On the generation of regular long waves in numerical wave flumes based on the particle finite element method. Journal of Hydraulic Research, 55(4), 538-556. https://doi.org/10.1080/ 00221686.2016 .1275047

Oñate, E., Franci, A., \& Carbonell, J. M. (2014). Lagrangian formulation for finite element analysis of quasi-incompressible fluids with reduced mass losses. International Journal for Numerical Methods in Fluids, 74(10), 699-731. https://doi.org/10.1002/fld.3870

Oñate, E., Idelsohn, S. R., Celigueta, M. A., \& Rossi, R. (2008). Advances in the particle finite element method for the analysis of fluidmultibody interaction and bed erosion in free surface flows. Computer Methods in Applied Mechanics and Engineering, 197(19-20), $1777-1800$

Oñate, E., Idelsohn, S. R., Del Pin, F., \& Aubry, R. (2004). The particle finite element method-An overview. International Journal of Computational Methods, 01(02), 267-307. https://doi.org/10.1142/S0219876204000204

Pak, A., and Sarfaraz M., 2014. Lattice Boltzmann method for simulating impulsive water waves generated by landslides, Transactions on Civil Engineering (A), Scientia Iranica, 318-328.

Pastor, M., Haddad, B., Sorbino, G., Cuomo, S., \& Drempetic, V. (2009). A depth-integrated, coupled SPH model for flow-like landslides and related phenomena. International Journal for Numerical and Analytical Methods in Geomechanics, 33(2), 143-172. https://doi.org/ 10.1002/nag.705

Pinyol, N. M., Alvarado, M., Alonso, E. E., \& Zabala, F. (2017). Thermal effects in landslide mobility. Géotechnique., 68(6), 528-545.

Pudasaini, S. P. (2012). A general two-phase debris flow model. Journal of Geophysical Research, 117, F03010. https://doi.org/10.1029/ 2011JF002186

Qiu, L. C., Tian, L., Liu, X. J., \& Han, Y. (2019). A 3D multiple-relaxation-time LBM for modeling landslide-induced tsunami waves. Engineering Analysis with Boundary Elements, 102, 51-59. https://doi.org/10.1016/j.enganabound.2019.02.011 
Roberts, N. J., McKillop, R. J., Lawrence, M. S., Psutka, J. F., Clague, J. J., Brideau, M. A., \& Ward, B. C. (2013). Impacts of the 2007 landslide-generated tsunami in Chehalis Lake, Canada. In Landslide science and practice, (pp. 133-140). Berlin, Heidelberg: Springer. Ruffini, G., Heller, V., \& Briganti, R. (2019). Numerical modelling of landslide-tsunami propagation in a wide range of idealised water body geometries. Coastal Engineering, 103518.

Salazar, F., Irazábal, J., Larese, A., \& Oñate, E. (2016). Numerical modelling of landslide-generated waves with the particle finite element method (PFEM) and a non-Newtonian flow model. International Journal for Numerical and Analytical Methods in Geomechanics, 40(6), 809-826. https://doi.org/10.1002/nag.2428

Smith, R. C., Hill, J., Collins, G. S., Piggott, M. D., Kramer, S. C., Parkinson, S. D., \& Wilson, C. (2016). Comparing approaches for numerical modelling of tsunami generation by deformable submarine slides. Ocean Modelling, 100, 125-140. https://doi.org/10.1016/j. ocemod.2016.02.007

Yerro, A., Soga, K., \& Bray, J. (2019). Runout evaluation of the Oso landslide with the material point method. Canadian Geotechnical Journal, 56(9), 1304-1317. https://doi.org/10.1139/cgj-2017-0630

Zhang, X., Krabbenhoft, K., Sheng, D., \& Li, W. (2015). Numerical simulation of a flow-like landslide using the particle finite element method. Computational Mechanics, 55(1), 167-177. https://doi.org/10.1007/s00466-014-1088-z

Zhang, X., Oñate, E., Torres, S. A. G., Bleyer, J., \& Krabbenhoft, K. (2019). A unified Lagrangian formulation for solid and fluid dynamics and its possibility for modelling submarine landslides and their consequences. Computer Methods in Applied Mechanics and Engineering, 343, 314-338. https://doi.org/10.1016/j.cma.2018.07.043

Zweifel, A., Hager, W. H., \& Minor, H. E. (2006). Plane impulse waves in reservoirs. Journal of Waterway, Port, Coastal, and Ocean Engineering, 132(5), 358-368. https://doi.org/10.1061/(ASCE)0733-950X(2006)132:5(358) 